\title{
Effect of Hydrocortisone on the Metabolism of Phosphatidylcholine in Maternal and Fetal Rabbit Lungs and Livers
}

\author{
FRANCIS H. C. TSAO (33), GARY R. GUTCHER, AND RICHARD D. ZACHMAN \\ Department of Pediatrics of the University of Wisconsin, and The Wisconsin Perinatal Center, Madison, Wisconsin, \\ USA
}

\section{Summary}

It has been observed that glucocorticoids stimulate fetal lung maturation. This study examined the effects of glucocorticoids on the phosphatidylcholine (PC) metabolism in maternal and fetal lungs and livers. At 24 days of gestation, pregnant does were injected im with either hydrocortisone or an equal volume of saline. At 27 days of gestation, the maternal and fetal lungs and livers were removed for study. Maternal hydrocortisone treatment significantly decreased the fetal body weight and lung weight, but had no effect on the weights of fetal liver or the ratios of maternal lung/body or liver/body weights. Concentrations of protein, total phospholipids, or PC of fetal lung and liver and of maternal liver were not affected by hydrocortisone. However, the amounts of maternal lung protein, total phospholipids, and PC were significantly increased. No stimulation by hydrocortisone was seen in the specific activities of the enzymes: choline kinase, phosphocholine cytidyltransferase, and choline phosphotransferase of cytidine 5'-diphosphocholine (CDP-choline) pathway and lysoPC-lysoPC acyltransferase, lysophospholipase, and acyl-CoA lysoPC acyltransferase of PC-lysoPC cycle pathway.

Maternal administration of hydrocortisone stimulated the incorporation of [methyl- ${ }^{14} \mathrm{C}$ ] choline into fetal lung PC. Additionally, hydrocortisone also accelerated the secretion of $\mathrm{PC}$ from maternal lung tissue. The acceleration of the secretion of $P C$ was not observed in the fetal lung tissue, possibly because of a low basal secretory rate. The acceleration of $P C$ secretion by hydrocortisone in maternal lung may suggest a relation of this mechanism to the fetal lung maturation affected by steroids.

\section{Speculation}

One biochemical effect of antenatal maternal hydrocortisone is the acceleration of choline incorporation into fetal lung PC. Maternally administered glucocorticoids, in addition to affecting fetal lung, might also affect maternal lung and liver PC metabolism by alteration of enzyme activity or changing turnover or transfer rates. Though studied indirectly, hydrocortisone might stimulate the secretion of lung PC onto the alveolar surface.

Lung surfactant is normally layered at the air-water interface of alveoli and stabilizes alveolar deflation during respiration. Phosphatidylcholine (1,2-diacyl-sn-glycero-3-phosphocholine) is the major lung surface-active component $(9,29)$. Insufficiency of this phospholipid in lungs of neonates is generally related to the respiratory distress syndrome (RDS) (7).

A number of studies have demonstrated that maternally administered glucocorticoids in humans can decrease RDS $(11,17)$ and increase the surface active material in tracheal efflux (21). Glucorticoids used in animal models have increased fetal lung surfactant $(4,5,8,16,23)$, increased the incorporation of choline into PC $(1,2,8,22,25)$, accelerated differentiation of alveolar epithelial cells in the fetal lung $(15,18,30)$, and increased fetal lung volume density of air space $(12,13)$. Lung PC is mainly synthesized by the CDP-choline pathway, and possibly remodeled by the deacylation-reacylation and deacylation-transacylation pathways (PClysoPC cycle pathway) to form the highly disaturated PC $(9,29)$. Several studies have suggested that the acceleration of fetal lung surfactant by prenatal administration of glucocorticoids is related to the induction of the enzymes of these pathways $(8,20,23)$. However, some studies on the enzyme induction by steroids have shown discrepant results $(2,22-24)$.

Although glucocorticoids stimulate the amount of PC in tracheal efflux of human fetal lungs (21) and in the pulmonary fluid of saline lavage of fetal rabbits (23), the effect of steroids on the secretory mechanism of lung PC has not been studied. Furthermore, none of the studies noted previously have reported what effects antenatal glucocorticoids might have on the metabolism of PC in maternal lung. Finally, the effects of glucocorticoids on PC metabolism in the liver of mother or fetus have not been reported.

The objective of this study was to investigate the effects of antenatal maternal steroids on PC metabolism in maternal lung and liver, in comparison to effects on fetal PC metabolism.

\section{MATERIALS AND METHODS}

\section{ANIMALS}

Beginning on the 24th day of gestation, pregnant New Zealand rabbits were injected im with $0.65 \mathrm{mg} / \mathrm{kg}$ of hydrocortisone phosphate (Merck, Sharp and Dohme, West Point, PA) every $8 \mathrm{hr}$ for 3 days as described by Barrett et al. (1). Control does received an equal volume of normal saline. The weight of food consumed by the animals was recorded each morning. At 27 days of gestation, the does were anesthetized with iv pentobarbitol and killed during thoracotomy. The fetuses were removed rapidly from the amniotic sac and their tracheas were clamped immediately to prevent respiration. After measuring weight of each fetus, the animal was then exsanguinated by cutting through the abdomen. The lungs and liver were removed. Both fetal lungs and liver were kept in ice cold saline. The maternal lungs and liver were perfused with cold saline immediately after removal. Subsequently, bronchial tissue of fetal lung and liver (an average of 6 fetuses per doe), were weighed. Each organ was minced and homogenized in 5 volumes of $0.25 \mathrm{M}$ sucrose in a Potter-Elvehjem homogenizer (clearance 0.005-0.007 inch) with 10 strokes at high speed in an ice bath. The homogenate was filtered through two layers of cheesecloth, and the filtrate was used for enzyme assay and protein and phospholipid analyses. Microsomes were prepared by centrifuging the homogenate at $12,500 \times \mathrm{g}$ for $20 \mathrm{~min}$ and subsequently centrifuging the supernatant at $105,000 \times \mathrm{g}$ for $60 \mathrm{~min}$.

\section{ENZYME ASSAY AND PROTEIN AND PHOSPHOLIPID ANALYSES}

Enzymes of CDP-choline pathway: choline kinase (EC 2.7.1.32), phosphocholine cytidyltransferase (EC 2.7.7.15), and choline phosphotransferase (EC 2.7.8.2), and enzymes of PC-lysoPC cycle 
pathway: lysophospholipase (EC 3.1.1.5), lysoPC-lysoPC acyltransferase, and acyl-CoA lysoPC acyltransferase (EC - 2.3.1.23) were assayed by procedures described previously $(27,28)$. Acyl$\mathrm{CoA}$ lysoPC acyltransferase was assayed in the lung microsomal fraction. Protein concentrations in the homogenate and microsomes and the amount of phospholipid in the homogenate were determined by the established methods (27).

\section{TISSUE MINCE EXPERIMENT}

Study of the incorporation of [methyl- ${ }^{14} \mathrm{C}$ ]-choline into lung PC was conducted in the following manner. Lung minces of $0.3 \mathrm{~g}$ tissue removed from upper and lower lobes of both lungs of does or fetuses were preincubated in a screw-capped reaction tube in 2 $\mathrm{ml} \mathrm{Krebs-Ringer} \mathrm{bicarbonate} \mathrm{buffer} \mathrm{(} \mathrm{pH} \mathrm{7.4)}$ at $37^{\circ}$ for $10 \mathrm{~min}$. Additional $2 \mathrm{ml}$ Krebs-Ringer buffer containing $1 \mu \mathrm{ci}$ [methyl${ }^{14} \mathrm{C}$ )-choline (specific radioactivity: $58 \mu \mathrm{ci} / \mu$ mole) (ICN Chemical and Radioisotope Division, Irvine, CA) was added to the preincubated solution. The reaction mixture was then incubated at $37^{\circ}$ for an additional $1 \mathrm{hr}$ in a shaking waterbath. At the end of the reaction, the reaction tube was placed in an ice bath, and the medium was removed immediately with a Pasteur pipette and filtered through two layers of cheesecloth. The filtrate was centrifuged at $600 \times \mathrm{g}$ for $5 \mathrm{~min}$ to remove debris. After the medium was removed, tissues in the reaction tube were washed thoroughly with $10 \mathrm{ml}$ ice-cold saline three times, and the washings were discarded. The tissue minces were then homogenized in $1.5 \mathrm{ml}$ saline; the homogenate was filtered through two layers of cheesecloth. The concentrations of proteins, total phospholipids, and PC of both medium and homogenate were analyzed (27). Radioactiv- ities of $\mathrm{PC}$ in $0.3 \mathrm{ml}$ homogenate and $3 \mathrm{ml}$ medium were determined separately. All experiments were carried out in duplicate.

\section{RESULTS}

Maternally administered hydrocortisone reduced the weights of rabbit fetal body $(P<0.01)$ and lung $(P<0.02)$ (Table 1$)$. The ratio of lung weight/body weight was not affected because both body weight and lung weight decreased to the same degree. Maternal lung weight, maternal liver weight, and fetal liver weight were not significantly affected by hydrocortisone. There was no difference in the amount or quality of food consumed by the control and hydrocortisone-treated rabbits. The reduction of fetal body weight and lung weight was, therefore, not related to the maternal diet.

The concentrations of protein ( $\mathrm{mg} / \mathrm{g}$ wet tissue), total phospholipids, and PC ( $\mu \mathrm{mole} / \mathrm{g}$ wet tissue) in the fetal lung were not affected by hydrocortisone, but they increased in the hydrocortisone-treated maternal lung $(P<0.01-0.05)$ (Table 2). However, if the concentration of phospholipid or PC was calculated based on $\mu \mathrm{mole} / \mathrm{mg}$ protein, no significant increase of phospholipid or $\mathrm{PC}$ in the maternal lung was observed because the increased amount of protein paralleled the increase of phospholipid or PC. The concentrations of protein, total phospholipids, and PC in both maternal and fetal livers were not affected.

No CDP-choline pathway enzyme activities or PC-lysoPC cycle pathway enzyme activities in the maternal lung or liver and fetal lung or liver were induced by maternally administered hydrocortisone (Table 3). Rather, phosphocholine cytidyltransferase activity was reduced in fetal lung $(P<0.05)$ and liver $(P<0.02)$ of

Table 1. Effect of hydrocortisone on the weights of maternal and fetal bodies, lungs, and livers ${ }^{1}$

\begin{tabular}{|c|c|c|c|c|c|}
\hline & Control $^{2}$ & $(n)$ & Cortisol $^{2}$ & $(n)$ & $P^{3}$ \\
\hline \multicolumn{6}{|l|}{ Fetus } \\
\hline Body wt (g/fetus) & $24.49 \pm 3.50$ & (49) & $21.85 \pm 3.55$ & (38) & $<0.01$ \\
\hline \multicolumn{6}{|l|}{ Tissue wt ( $\mathrm{g} /$ fetus) } \\
\hline Lung & $0.81 \pm 0.16$ & (9) & $0.60 \pm 0.19$ & (9) & $<0.02$ \\
\hline Liver & $2.19 \pm 0.29$ & (5) & $1.66 \pm 0.47$ & (5) & NS \\
\hline Lung wt/body wt & $0.028 \pm 0.002$ & (9) & $0.025 \pm 0.006$ & (9) & NS \\
\hline \multicolumn{6}{|l|}{ Doe } \\
\hline \multicolumn{6}{|c|}{ Tissue wt ( $\mathrm{g}$ tissue $/ \mathrm{kg}$ body) } \\
\hline Lung & $3.53 \pm 0.62$ & (6) & $3.52 \pm 1.06$ & (6) & NS \\
\hline Liver & $26.37 \pm 7.95$ & (5) & $41.74 \pm 13.12$ & (5) & NS \\
\hline
\end{tabular}

' Values are means $\pm \mathrm{SD}$ of the numbers in the parentheses.

${ }^{2}$ Statistical significance between the control and the hydrocortisone-treated samples was determined from two-tailed analysis of unpaired $t$-tests.

${ }^{3} \mathrm{NS}$, not significant $(P>0.05)$.

Table 2. Effect of hydrocortisone on the concentrations of protein, total phospholipids, and phosphatidylcholine of maternal and fetal

\begin{tabular}{|c|c|c|c|c|c|c|c|c|}
\hline & \multicolumn{4}{|c|}{ Doe } & \multicolumn{4}{|c|}{ Fetus } \\
\hline & Control $^{2}$ & Cortisol $^{2}$ & $(n)$ & $P^{3}$ & Control $^{2}$ & Cortisol $^{2}$ & $(n)$ & $P^{3}$ \\
\hline \multicolumn{9}{|l|}{ Lung } \\
\hline $\begin{array}{l}\text { Protein }(\mathrm{mg} / \mathrm{g} \text { wet tissue) } \\
\text { Phospholipid ( } \mu \text { mole/g wet tis- } \\
\text { sue) }\end{array}$ & $38.56 \pm 3.46$ & $44.02 \pm 7.62$ & $(10)$ & $<0.05$ & $35.91 \pm 7.28$ & $35.96 \pm 6.25$ & (9) & NS \\
\hline Total & $14.75 \pm 3.40$ & $18.89 \pm 3.61$ & $(10)$ & $<0.02$ & $6.13 \pm 1.52$ & $5.19 \pm 1.29$ & $(8)$ & NS \\
\hline PC & $8.52 \pm 1.66$ & $11.24 \pm 1.89$ & $(10)$ & $<0.01$ & $2.95 \pm 0.69$ & $2.26 \pm 0.50$ & (8) & NS \\
\hline \multicolumn{9}{|l|}{ Liver } \\
\hline $\begin{array}{l}\text { Protein }(\mathrm{mg} / \mathrm{g} \text { wet tissue) } \\
\text { Phospholipid ( } \mu \text { mole/g wet tis- } \\
\text { sue) }\end{array}$ & $95.05 \pm 13.71$ & $93.86 \pm 13.64$ & (5) & NS & $92.25 \pm 7.69$ & $90.25 \pm 8.58$ & (5) & NS \\
\hline Total & $23.78 \pm 4.75$ & $23.24 \pm 3.54$ & (5) & NS & $10.15 \pm 1.69$ & $10.52 \pm 2.30$ & (5) & NS \\
\hline PC & $10.93 \pm 1.95$ & $9.80 \pm 1.49$ & $(5)$ & NS & $5.07 \pm 0.81$ & $4.73 \pm 1.00$ & (5) & NS \\
\hline
\end{tabular}

' Values are means \pm SD of $n$ experiments shown in the parentheses.

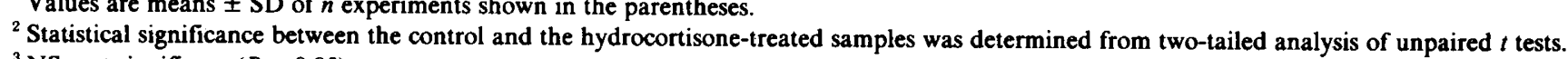

${ }^{3}$ NS, not significant $(P>0.05)$. 
Table 3. Hydrocortisone effect on the specific activities of CDP-choline pathway enzymes and phosphatidylcholinelysophosphatidylcholine cycle pathway enzymes in the maternal and fetal rabbit lungs and livers 1,2

Specific activity (nmole/mg protein/min)

\begin{tabular}{|c|c|c|c|c|c|c|c|c|}
\hline & \multicolumn{4}{|c|}{ Doe } & \multicolumn{4}{|c|}{ Fetus } \\
\hline & Control & Cortisol & $(n)$ & $P$ & Control & Cortisol & $(n)$ & $P$ \\
\hline \multicolumn{9}{|l|}{ Lung ${ }^{3}$} \\
\hline CK & $0.83 \pm 0.18$ & $1.23 \pm 0.68$ & (4) & NS & $1.75 \pm 0.62$ & $1.32 \pm 0.64$ & (5) & NS \\
\hline CyT $\left(10^{-2}\right)$ & $8.56 \pm 2.42$ & $9.61 \pm 3.98$ & (6) & NS & $19.04 \pm 5.34$ & $12.22 \pm 4.54$ & (6) & $<0.05$ \\
\hline CPT $\left(10^{-2}\right)$ & $6.70 \pm 1.88$ & $7.33 \pm 1.65$ & (6) & NS & $12.23 \pm 1.64$ & $10.12 \pm 2.84$ & (6) & NS \\
\hline LAT & $14.57 \pm 5.97$ & $11.12 \pm 4.48$ & (9) & NS & $1.03 \pm 0.66$ & $1.67 \pm 1.11$ & (6) & NS \\
\hline LPL & $29.72 \pm 9.53$ & $15.71 \pm 6.73$ & (9) & $<0.01$ & $2.96 \pm 0.96$ & $3.85 \pm 1.11$ & (6) & NS \\
\hline acyl-CoA LAT & $6.34 \pm 1.58$ & $6.06 \pm 1.03$ & (4) & NS & $0.63 \pm 0.38$ & $0.62 \pm 0.43$ & (5) & NS \\
\hline \multicolumn{9}{|l|}{ Liver } \\
\hline $\mathrm{CK}$ & $0.51 \pm 0.05$ & $0.89 \pm 0.14$ & (4) & NS & $0.91 \pm 0.11$ & $1.09 \pm 0.22$ & (4) & NS \\
\hline CyT $\left(10^{-2}\right)$ & $11.79 \pm 6.28$ & $10.07 \pm 2.34$ & (5) & NS & $5.13 \pm 1.30$ & $3.26 \pm 1.13$ & (5) & $<0.02$ \\
\hline CPT $\left(10^{-2}\right)$ & $27.05 \pm 9.06$ & $16.95 \pm 1.19$ & (5) & $<0.05$ & $12.12 \pm 3.73$ & $13.66 \pm 1.85$ & (5) & NS \\
\hline LAT & $1.20 \pm 0.37$ & $0.42 \pm 0.34$ & (8) & $<0.001$ & $7.26 \pm 2.16$ & $6.32 \pm 1.64$ & (5) & NS \\
\hline LPL & $2.87 \pm 0.86$ & $1.76 \pm 0.66$ & (8) & $<0.01$ & $9.12 \pm 3.73$ & $7.53 \pm 2.34$ & (5) & NS \\
\hline
\end{tabular}

${ }^{1}$ Values are means $\pm \mathrm{SD}$ of $n$ experiments shown in the parentheses

${ }^{2}$ Statistical significance between the control and the hydrocortisone-treated samples was determined from two-tailed analysis of unpaired $t$ tests. NS, not significant $(P<0.05)$

${ }^{3}$ CK, choline kinase; CyT, cytidyltransferase; CPT, cholinephosphotransferase; LAT lysophosphatidylcholine-lysophosphatidylcholine acyltransferase; LPL, lysophospholipase; acyl-CoA LAT, acylCoA:lysophosphatidylcholine acyltransferase.

hydrocortisone-treated mothers. Furthermore, hydrocortisone also reduced the specific activity of lysophospholipase in both maternal lung and liver $(p<0.01)$ and the specific activities of choline phosphotransferase $(P<0.05)$ and lysoPC-lysoPC acyltransferase $(P<0.001)$ in the maternal liver.

In the experiment with tissue minces, the absolute values of choline uptake and PC secretion in both control and cortisoltreated lungs varied greatly from day to day, probably as a result of the inconsistancy of making tissue minces. Therefore, the rate of the incorporation of [methyl ${ }^{14} \mathrm{C}$ ]-choline into $\mathrm{PC}$ was expressed as the ratio of $\mathrm{PC}$ in the hydrocortisone-treated lung to the PC of the control lung (Table 4). Values are expressed as means $\pm 95 \%$ confidence limits. Similarly, the secretory rate of PC from lung tissue was expressed as the ratio of the radioactivity of PC in the treated medium over that of the control medium (Table 4). The ratio of choline incorporation into fetal lung $\mathrm{PC}$ and maternal lung PC was $1.33 \pm 0.15$ and $1.13 \pm 0.28$, respectively. Maternally administered hydrocortisone stimulated the incorporation of choline into fetal lung PC, but did not elevate the incorporation of choline into maternal lung PC. On the other hand, maternally administered hydrocortisone accelerated the secretion of $\mathrm{PC}$ from maternal lung tissue into the incubation medium, but had not affected the secretion of fetal lung PC. The ratio of the secretory rate of $\mathrm{PC}$ of treated/control was $1.77 \pm 0.57$ for the adult and $0.70 \pm 0.65$ for the fetus. The secretory rate of PC from fetal lung tissue into the medium was very low; the radioactivity of PC in the medium of the fetal experiment was near that of the control blank. Thus, the wide $95 \%$ confidence limit was obtained for fetal PC release.

\section{DISCUSSION}

Maternal administration of hydrocortisone caused significant reductions in fetal body weight and fetal lung weight (Table 1). These results confirm others' observations $(3,18,22,25)$ and indicate that the dose and timing of the maternally administered hydrocortisone in this experiment was sufficient to cause some effect on the fetuses. The reduction of glucocorticoid-treated fetal lung weight probably resulted from a decrease of the water content (3) or an inhibition of cell proliferation $(3,14)$. Loss of water content should also have produced a significant increase in the fetal lung protein concentration (22), but an increase of protein concentration was not observed in this study.
Table 4. Hydrocortisone effect on the choline incorporation into phosphatidylcholine in the maternal and fetal rabbit lung tissues and on the secretion of lung phosphatidylcholine

Ratio of the radioactivity of phosphatidylcholine cortisol/control

\begin{tabular}{llc}
\cline { 2 - 3 } Animals & Lung tissue $(n)$ & Medium $(n)$ \\
\hline Doe & $1.13 \pm 0.28(7)$ & $1.77 \pm 0.57(6)$ \\
Fetus & $1.33 \pm 0.15(6)$ & $0.70 \pm 0.65(4)$ \\
\hline
\end{tabular}

' Values are means $\pm 95 \%$ confidence limits from $n$ experiments.

Some studies have shown that glucocorticoids increase the concentration of $P C$ in fetal lung tissue $(8,23)$. However, this was not apparent in this study (Table 2 ), nor has it been consistently observed by others $(1,10,12,25)$. These different observations could result from diverse techniques of lung PC measurement based on either dry lung $(8,23)$ or wet lung (this study, 1, 10, 12, 25 ). Unlike the fetal lung, the concentrations of protein, total phospholipids, and PC in the hydrocortisone-treated maternal lung were significantly increased. An increase in the amount of protein or PC was not associated with a reduction of water content in the lung because the lung weight/body weight ratio of the hydrocortisone treated doe was the same as the control value (Table 1). The mechanism of this acceleration is not clear.

Although the stimulation of the formation of fetal lung PC by glucocorticoids has been suggested to result from the induction of the CDP-choline pathway enzymes $(8,20,23)$, the reported observations of enzyme induction are discrepant. Some of our results are in agreement with those of others, because the activities of choline phosphotransferase $(2,22,23)$ and acyl-CoA:lysoPC acyltransferase (24) in fetal lung were not enhanced by glucocorticords. In contrast to the observation of Rooney et al. (23) that phosphocholine cytidyltransferase activity was induced by glucocorticoid, the authors found that this enzymatic activity in both fetal lung and liver was reduced after maternal hydrocortisone treatment. The specific activity of phosphocholine cytidyltransferase in fetal rat lung was also not stimulated by dexamethasone (20). These discrepant results could be due to the different methods of enzyme assay or the different methods of steroid treatment. For instance, glucocorticoids injected in 24-day and 25-day gestational fetuses affected differently the enzymatic activities of glycerophosphate 
Table 5. Summary of published results of cortisol effects on fetal lung phospholipid metabolic pathway enzymes

\begin{tabular}{|c|c|c|c|c|c|c|}
\hline Enzymes' & $\begin{array}{c}\text { Breiher } \\
\text { et al. }(2)^{2,3} \\
\end{array}$ & $\begin{array}{c}\text { Farrell and } \\
\text { Zachman }(8)^{3.4}\end{array}$ & $\begin{array}{c}\text { Oldenborg and } \\
\text { VanGolde (20), } 5 \\
\end{array}$ & $\begin{array}{l}\text { Possmayer } \\
\text { et al. }(22)^{3,4}\end{array}$ & $\begin{array}{c}\text { Rooney et al. } \\
(23,24)^{3,4}\end{array}$ & $\begin{array}{l}\text { Present } \\
\text { study }^{2,3}\end{array}$ \\
\hline \multicolumn{7}{|l|}{ CDP-choline pathway } \\
\hline CK & $\mathrm{NM}^{6}$ & NM & $-{ }^{7}$ & NM & - & - \\
\hline CyT & NM & NM & - & NM & + & $\downarrow^{8}$ \\
\hline CPT & - & $+^{9}$ & + & - & - & - \\
\hline \multicolumn{7}{|l|}{ PC-lysoPC cycle pathway } \\
\hline LAT & NM & NM & - & NM & NM & - \\
\hline LPL & NM & NM & NM & NM & NM & - \\
\hline AcylCoA:LAT & NM & NM & + & NM & $\begin{array}{l}+(23) \\
-(24)\end{array}$ & - \\
\hline \multicolumn{7}{|l|}{$\begin{array}{l}\text { PG pathway } \\
\text { glycerophosphate }\end{array}$} \\
\hline phosphatidyl-transferase & - & NM & $\mathbf{N M}$ & - & $\begin{array}{l}-(23) \\
+(24)\end{array}$ & NM \\
\hline Phosphatidic acid phosphatase & + & NM & NM & + & NM & NM \\
\hline $\begin{array}{l}\text { CK: choline kinase; CyT: ph } \\
\text { line acyltransferase; LPL: lysopt } \\
{ }^{2} \text { Maternal administration of } \\
{ }^{3} \text { Rabbit. } \\
{ }^{4} \text { Direct fetal injection of sterc } \\
{ }^{5} \text { Rat. } \\
{ }^{6} \mathrm{NM}=\text { not measured. } \\
{ }^{7}-=\text { no induction noted. } \\
{ }^{8} \downarrow=\text { decreased. } \\
{ }^{9}+=\text { induction noted. }\end{array}$ & $\begin{array}{l}\text { ocholine cytid } \\
\text { olipase; acyl- } \\
\text { ds. }\end{array}$ & $\begin{array}{l}\text { ansferase; CPT: ch } \\
\text { LAT: acyl-CoA } 1\end{array}$ & $\begin{array}{l}\text { nephosphotransfera } \\
\text { ophosphatidylcholin }\end{array}$ & $\begin{array}{l}\text { T: lysophosph } \\
\text { Itransferase; PC }\end{array}$ & $\begin{array}{l}\text { choline-lysopho } \\
\text { sphatidylglycer }\end{array}$ & atidylcho- \\
\hline
\end{tabular}

phosphatidyltransferase and acyl-CoA:lysoPC acyltransferase $(23$ 24). A summary of published results of cortisol effects on fetal lung phospholipid metabolic pathway enzymes is listed in Table 5 . These results were obtained from different species of animals, diverse techniques of steroid treatment, and with different doses. It is clearly not easy to draw final conclusions on the effects of glucocorticoids on the enzyme induction. It would be ideal, but experimentally difficult, to carry out the assays of all the enzymes of the de novo biosynthetic pathway and the branch pathways of $\mathrm{PC}$ at different gestations, different durations and techniques of steroid treatment, and varying times after treatment. In addition, because the effect of glucocorticoids on fetal lung maturation is mainly related to the acceleration of type II cells $(15,18,30)$, the use of whole lung tissues may not be sensitive enough for enzyme induction studies.

Clinically, there is a concern that administering short-term pharmacologic doses of steroids to mothers to enhance fetal lung maturation might have unwanted side effects on the mother, and some detrimental effects on placental function have been shown (19). To date, no studies report possible biochemical sequelae on the mother when attempting to alter fetal lung maturation with steroids. Likewise, no previous reports have included possible effects of steroids on phospholipid metabolism in fetal liver. Under the experimental conditions described above, hydrocortisone reduced the activities of choline phosphotransferase, lysophospholipase, and lysoPC-lysoPC acyltransferase in maternal liver and lysophospholipase in maternal lung. Whether these changes had enough effect on the phospholipid metabolism in maternal lung and liver to have physiologic or clinical significance is unknown, but the does appeared well throughout the study.

Activities of PC-lysoPC cycle pathway enzymes of 27-day fetal lung were 5- to 10-fold lower than that of the maternal lung (Table 3 ), confirming our earlier observations (28). However, the activities of lysophospholipase and lysoPC-lysoPC acyltransferase in fetal liver were 3- and 6-fold higher, respectively, than that in the maternal liver. The specific activities of the CDP-choline pathway enzymes in fetal lung were higher than that in the maternal lung. In contrast, they were lower in fetal liver than in the maternal liver. These opposite patterns of the specific activities of the enzymes of CDP-choline pathway and PC-lysoPC cycle pathway in rabbit maternal and fetal lungs and livers might suggest some differences in the development of PC synthesis or degradation in these two organs.

In contrast to the discrepant results of the effect of steroids on specific enzyme induction in fetal lung, glucocorticoids have always stimulated the general incorporation of choline or other substrates into fetal lung $P C$ in vivo (1), in tissue slices $(2,8,22$, $25)$, and in tissue culture $(6,26)$. In addition to specific enzyme induction, glucocorticoids might affect substrate uptake by the intact cells, not just choline, but also other substances, such as the incorporation of glucose into glycogen and $\mathrm{PC}(10)$, palmitate into PC (25), and ethanolamine into phosphatidylethanolamine (22).

Though choline incorporation into fetal lung PC was accelerated by cortisol, the incorporation of choline into maternal lung PC was not significantly altered by this steroid. However, the hydrocortisone-treated maternal lung tissue released $\mathrm{PC}$ faster than that of the control (Table 4). It is possible that the PC isolated from the incubation medium might come from contamination by broken cells. This cannot be completely excluded under the experimental conditions. However, because the radioactivities of PC of the control and hydrocortisone-treated lung tissues were the same, contamination by broken cells should not result in a higher radioactivity of $\mathrm{PC}$ in the steroid-treated medium than that in the control. It is not yet known whether the acceleration of the secretion of PC observed in this study can be extrapolated to the observation of increasing surfactant at the alveolar surface of fetal lung affected by glucocorticoids. Unfortunately, the acceleration of PC secretion from the treated fetal lung tissue were not observed, possibly because the basal rate of PC secretion from fetal lung tissue was so low, hence, rendering it difficult to measure any small increase.

Two possible explanations for the different results of choline incorporation and PC secretion between maternal and fetal lungs are: 1 ) in the hydrocortisone treated does, $\mathrm{PC}$ release from tissues into the medium seemed to be rapid enough to perhaps mask any stimulation of choline incorporation into PC in the tissues; and 2) because maternal lung and fetal lung differ morphologically (15), the effects of glucocorticoids on choline uptake by the cell and incorporation into $\mathrm{PC}$ and the secretion of $\mathrm{PC}$ may not be the same. For instance, the stimulation of choline incorporation into fetal lung PC may have resulted from the acceleration of the differentiation of type II cells, a process which presumably is not 
happening in maternal lung. More studies are clearly necessary to establish the mechanisms of the effect of steroid on fetal lung maturation in regard to the substrate uptake and product secretion of lung surfactant.

\section{CONCLUSION}

Administration of hydrocortisone to pregnant rabbits caused a decrease in weights of fetal body and lung and an increase in the incorporation of choline into fetal lung PC. The authors found no induction of the enzymes related to the incorporation of choline into PC in fetal lung. Also, there was no stimulation of any enzymatic activity of CDP-choline pathway or PC-lysoPC cycle pathway in maternal lung and liver or fetal liver. In addition to the acceleration of choline incorporation into fetal lung PC by the cortisol, hydrocortisone also significantly stimulated the secretion of lung PC affected by glucocorticoids may also be related to apparent fetal lung maturation.

\section{REFERENCES AND NOTES}

1. Barrett, C. T., Sevanian, A., Lavin, N., and Kaplan, S. A.: Role of adenosine 3',5'-monophosphate in maturation of fetal lungs. Pediatr. Res., 10:621 (1976).

2. Brehier, A., Benson, B. J., Williams, M. C., Mason, R. J., and Ballard, P. L. Corticosteroid induction of phosphatidic acid phosphatase in fetal rabbit lung Biochem. Biophys. Res. Commun., 77: 883 (1977).

3. Carson, S. H., Taeusch, Jr., H. W., and Avery, M. E.: Inhibition of lung cell division after hydrocortisone injection into fetal rabbits. J. Appl. Physiol., 34: 660 (1973).

4. DeLemos, R. A., and McLaughlin, G. W.: Induction of the pulmonary surfactant in the fetal primate by the intrauterine administration of corticosteroids. Pediatr. Res., 7: 425 (1973).

5. DeLemos, R. A., Shermeta, D. W., Knelson, J. H., Kotas, R. V., and Avery, M. E.: Acceleration of appearance of pulmonary surfactant in the fetal lamb by administration of corticosteroids. Am. Rev. Respir. Dis., 102: 459 (1970).

6. Ekelund, L., Arvidson, G., Emanuelsson, H., Myhrberg, H., and Astedt, B.: Effect of cortisol on human fetal lung in organ culture. Cell Tiss. Res., I63: 263 (1975).

7. Farrell, P. M., and Avery, M. E.: Hyaline membrane disease. Am. Rev. Respir Dis., $/ 11$ : 657 (1975).

8. Farrell, P. M., and Zachman, R. D.: Induction of choline phosphotransferase and lecithin synthesis in the fetal lung by corticosteroids. Science, 179: 297 (1973).

9. Frosolono, M. F.: Lung. In: F. Snyder: Lipid Metabolism in Mammals, Vol. 2. p. 1 (Plenum Press, New York, 1977).

10. Gilden, C., Sevanian, A., Tierney, D. F., Kaplan, S. A., and Barrett, C. T.: Regulation of fetal lung phosphatidylcholine synthesis by cortisol: role of glycogen and glucose. Pediatr. Res., 11: 845 (1977)

11. Howie, R. N., and Liggins, G. C.: Prevention of respiratory distress syndrome in premature infants by antepartum glucocorticoid treatment. In: C. A. Villee, D. B. Villee, and J. Zuckerman: Respiratory Distress Syndrome, p. 369-380 (Academic Press, New York, 1973).

12. Johnson, J. W. C., Mitzner, W., London, W. T., Palmer, A. E., Scott, R., Kearney, K.: Glucocorticoids and the rhesus fetal lung. Am. J. Obstet. Gynecol., 130. 905 (1978).
13. Kauffman, S. L.: Acceleration of canalicular development in lungs of fetal mice exposed transplacentally to dexamethasone. Lab. Invest.. 36: 395 (1977).

14. Kauffman, S. L.: Proliferation, growth, and differentiation of pulmonary epithelium in fetal mouse lung exposed transplacentally to dexamethasone. Lab. Invest., 37: 497 (1977).

15. Kikkawa, Y., Kaibara, M., Motoyama, E. K., Orzalesi, M. M., and Cook, C. D.: Morphologic development of fetal rabbit lung and its acceleration with cortisol. Am. J. Pathol., 64: 423 (1971).

16. Kotas. R. V., Fletcher, B. D., Torday, J.. and Avery, M. E.: Evidence for independent regulators of organ maturation in fetal rabbits. Pediatrics. 47: 57 (197I).

17. Liggins, G. C., and Howie, R. N.: A controlled trial of antepartum glucocorticoid treatment for prevention of the respiratory distress syndrome in premature infants. Pediatrics, 50: 515 (1972).

18. Motoyama, E. K., Orzalesi, M. M., Kikkawa, Y., Kaibara, M., Wu, B., Zigas, C. J., and Cook, C. D.: Effect of cortisol on the maturation of fetal rabbit lungs. Pediatrics, 48: 547 (1971).

19. Ohrlander, S. A. V.. Gennser, G. M., and Greenert, L.: Impact of betamethasone load given to pregnant women on endocrine balance of fetoplacental unit. Am. J. Obstet. Gynecol.. 123: 228 (1975).

20. Oldenborg, V., and VanGolde, L. M. G.: The enzymes of phosphatidylcholine biosynthesis in the fetal mouse lung. Effects of dexamethasone. Biochim. Biophys. Acta, 489: 454 (1977).

21. Platzker, A., Clements, J., and Tooley. W.: Surfactant development in the human fetal lungs. Clin. Res.. 19: 232 (1974)

22. Possmayer, F., Duwe, G., Metcalfe, R. Stewart-DeHaan. P. J., Wong, C., Las Heras, J., and Harding, P. G. R.: Cortisol induction of pulmonary maturation in the rabbit fetus. Biochem. J., 166: 485 (1977).

23. Rooney, S. A., Gobran, L., Gross, I., Wai-Lee, T. S., Nardone. L. L., and Motoyama, E. K.: Study on pulmonary surfactant. Effect of cortisol administration to fetal rabbits on lung phospholipid content, composition, and biosynthesis. Biochim. Biophys. Acta, 450: 121 (1976).

24. Rooney, S. A., Gross, I., Gassenheimer, L. N., and Motoyama, E. K.: Stimulation of glycerolphosphate phosphatidyltransferase activity in fetal rabbit lung by cortisol administration. Biochim. Biophys. Acta, 398: 433 (1975).

25. Russell, B. J., Nugent, L., and Chernick, V.: Effects of steroids on the enzymatic pathways of lecithin production in fetal rabbits. Biol. Neonate, 24: 306 (1974).

26. Smith. B. T., and Torday, J. S.: Factors affecting lecithin synthesis by fetal lung cells in culture. Pediatr. Res., 8: 848 (1974).

27. Tsao, F. H. C., and Zachman, R. D.: Phosphatidylcholine-lysophosphatidylcholine cycle pathway enzymes in rabbit lung. I. Subcellular localization and properties. Pediatr. Res., /1: 849 (1977).

28. Tsao, F. H. C., and Zachman, R. D.: Phosphatidylcholine-lysophosphatidylcholine cycle pathway enzymes of rabbit lung. II. Marked differences in the effect of gestational age on activity compared to the CDP-choline pathway. Pediatr. Res., I1: 858 (1977).

29. VanGolde, L. M. G.: Metabolism of phospholipids in the lung. Am. Rev. Respir Dis., 114: 977 (1976).

30. Wang. M. S., Kotas, R. V., Avery, M. E., and Thurlbeck, W. M.: Accelerated appearance of osmiophilic bodies in fetal lungs following steroid injection. J. Appl. Physiol., 30: 362 (1971).

31. The authors thank Susan J. Barnard and K. Jane Jaskowski for their technical assistance.

32. This research was supported by National Institutes of Health grant 5-R0I HL 17329-02 HED

33. Requests for reprints should be addressed to: F. H. C. Tsao, Ph.D., Department of Pediatrics. University of Wisconsin and the Wisconsin Perinatal Center, 202 S. Park St., Madison, WI 53715 (USA).

34. Received for publication March $8,1978$.

35. Accepted for publication September 26, 1978 